\title{
Meteorological factors associated with hand, foot and mouth disease in a Central Highlands province in Viet Nam: an ecological study
}

Hau Van Pham, ${ }^{a}$ Uyen Thi Ngoc Phan ${ }^{b}$ and Anh Nguyen Quynh Phamc

Correspondence to Hau Van Pham (email: hau.phamvan@gmail.com)

Background: Hand, foot and mouth disease (HFMD) is a public health problem in Viet Nam, and studies have reported seasonal fluctuation in the occurrence of HFMD. This study sought to describe the occurrence of HFMD and its associated meteorological factors in Dak Lak province, Viet Nam.

Methods: Monthly data on HFMD cases were collected from all commune health stations in Dak Lak province from 2012 through 2013. An HFMD case was defined as a brief febrile illness accompanied by a typical skin rash with or without mouth ulcers. Average temperature, maximum temperature, minimum temperature, humidity, rainfall, evaporation, sunshine duration and wind speed were recorded monthly at five local meteorological stations throughout Dak Lak. Data were aggregated at the district level, and the association between these meteorological factors and HFMD cases were examined by Poisson regression.

Results: In 2012 through 2013, there were 7128 HFMD patients in Dak Lak. The number of HFMD cases increased during the rainy season. An increased risk of HFMD was associated with higher average temperature (risk ratio and $95 \%$ confidence interval: $1.06 ; 1.03-1.08$ per $1{ }^{\circ} \mathrm{C}$ increase), higher rainfall (1.19; $1.14-1.24$ per $200 \mathrm{~mm}$ increase) and longer sunshine duration (1.14; 1.07-1.22 per 60 hours increase). The risk of HFMD was inversely associated with wind speed $(0.77 ; 0.73-0.81$ per $1 \mathrm{~m} / \mathrm{s}$ increase).

Conclusion: This study suggests that there is a significant association between HFMD occurrence and climate. Temperature, rainfall, wind speed and sunshine duration could be used as meteorological predictors of HFMD occurrence in Viet Nam's Central Highlands region. Intensified surveillance for HFMD during the rainy season is recommended.

$\mathrm{H}$ and, foot and mouth disease (HFMD) is an acute enterovirus infectious disease. HFMD has no vaccine or specific therapy thus far. Early detection of outbreaks, early recognition of severe HMFD and timely supportive treatment are among the key principles applied to minimize the burden of disease. ${ }^{1}$ HFMD is a major health problem in many countries, notably in the World Health Organization's (WHO) Western Pacific Region, including Viet Nam. ${ }^{1-3}$ In Viet Nam, the first HFMD epidemic was reported in Ho Chi Minh City in $2003,{ }^{4}$ it then gradually spread around the country until multiple significant outbreaks in 2010 caused national concern. Since 2011, HFMD has been included in the National Communicable Disease Surveillance System. According to data from the Viet Nam Ministry of Health in 2012, HFMD had the highest mortality among the notifiable communicable diseases under the General Department of Preventive Medicine, Ministry of Health, with 157391 cases and 45 deaths. ${ }^{5}$

Certain meteorological factors have been found to be associated with the occurrence of HFMD. Temperature had a positive association with the number of HFMD cases in studies. ${ }^{6-9}$ In Japan, the weekly number of HFMD cases rose by $11.2 \%$ when average temperatures increased $1{ }^{\circ} \mathrm{C} .{ }^{10}$ The relationship with humidity was inconsistent; some studies showed the risk of HFMD increased $0.51-4.7 \%$ when relative humidity elevated $1 \%,{ }^{6,8-10}$ while other studies reported that HFMD and humidity were not associated. ${ }^{11,12}$ The relationship between HFMD and rainfall is also inconsistent. A study in Guangdong supported a positive association between 
rainfall and HFMD, ${ }^{6}$ while two studies from Guangdong found a non-significant association. ${ }^{8,9}$ In China, when wind speed increased $1 \mathrm{~m} / \mathrm{s}$, the risk of HFMD increased 4.01\%. ${ }^{9}$ A study in Hong Kong SAR (China) also demonstrated that wind speed was positively associated with HFMD consultation rates. ${ }^{11}$ Most studies denoted positive associations with evaporation and sunshine and HFMD occurrence. ${ }^{6,11,13}$

In Viet Nam, the association between HFMD and climate parameters has not been well examined. A model including climate parameters could be used as an early surveillance system to predict annual HFMD epidemics. ${ }^{14}$ This study aimed to describe the occurrence of HFMD, and its association with meteorological factors in Dak Lak province in the Central Highlands region of Viet Nam.

\section{METHODS}

\section{Study setting}

An ecological study was conducted using data from January 2012 through December 2013 in Dak Lak province (total population: $\sim 1.8$ million). Dak Lak is located between $12^{\circ} 09^{\prime}-13^{\circ} 25^{\prime}$ north latitudes and $107^{\circ} 28^{\prime}-108^{\circ} 59^{\prime}$ east longitudes and shares a border with Cambodia (Fig. 1). The terrain is mainly relatively flat highland with an average altitude of about $500 \mathrm{~m}$ above sea level. Dak Lak has a tropical monsoon climate with two distinct seasons: the rainy season is usually from May through October and the dry season is from November through April. The rainy season typically receives $90 \%$ of the annual rainfall. The annual average rainfall is about $2000 \mathrm{~mm}$, and the annual average temperature ranges between $23^{\circ} \mathrm{C}$ and $24^{\circ} \mathrm{C}$. (Table 1 )

HFMD prevention and control activities in Dak Lak province were carried out under an unofficial multisectoral committee. Key activities included surveillance of HFMD with routine weekly reports, laboratory-based sentinel surveillance and monitoring of environmental risk factors for HFMD epidemics.

\section{Data collection}

The number of HFMD cases was collected from the Center for Disease Control of Dak Lak Province. These data were obtained through the Communicable Disease Surveillance System in Viet Nam from 2012 through $2013 .{ }^{15}$ Circular $54 / 2015 /$ TT-BYT mandates the reporting of HFMD by all levels of health care, from the commune health station to the national level.

According to the Viet Nam Ministry of Health protocol, ${ }^{15}$ mainly based on WHO recommendations, ${ }^{1}$ individuals suspected of having HFMD were those who meet the case definition as a brief febrile illness accompanied by a typical skin rash with or without mouth ulcers. Once identified, a patient was treated at the nearest health facility or transferred, depending on the severity of the condition, to a district or provincial hospital for further diagnosis and treatment. Total numbers of HFMD cases were recorded monthly during the surveillance period from 2012 through 2013. Meteorological data were provided by the hydro-meteorological forecast station of Dak Lak province. ${ }^{16}$ Average/maximum/minimum temperature $\left({ }^{\circ} \mathrm{C}\right)$, relative humidity $(\%)$, amount of rainfall $(\mathrm{mm})$, amount of evaporation (mm), duration of sunshine (hours) and average wind speed $(\mathrm{m} / \mathrm{s})$ were recorded daily from five stations of meteorology throughout Dak Lak province and averaged for each month.

\section{Data analysis}

The main aim of the data analysis was to determine if an association exists between the number of HFMD cases and the meteorological parameters. The outcome was the monthly number of HFMD cases in each district. The predictive variables were average temperature, maximum temperature, minimum temperature, humidity, rainfall, evaporation, sunshine duration and wind speed.

The study assumed that the distribution of HFMD cases followed the Poisson distribution as the number of HFMD cases was relatively small compared to the provincial population. Poisson regression was used to model the associations between the meteorological factors and the distribution of HFMD cases. Due to a variation of meteorological factors in season and location, in subsequent analyses, time (month, year) and area (district) were considered simultaneously in a multivariable model. The effects of meteorological variables were modelled as follows:

where $\boldsymbol{\beta}_{0}, \boldsymbol{\beta}_{1}, \boldsymbol{\beta}_{2}, \ldots, \boldsymbol{\beta}_{p}$, are regression coefficients $\lambda_{t}=\exp \left(\beta_{0}+\beta_{1} X_{t 1}+\beta_{2} X_{t 2}+\ldots+\beta_{p} X_{t p}\right)$

related to variables $\boldsymbol{x}_{t 0}, \boldsymbol{x}_{t 1}, \boldsymbol{x}_{t 2}, \ldots, \boldsymbol{x}_{t p}$, respectively (with $\boldsymbol{x}_{t 0}=\mathbf{0}$ ), and $\boldsymbol{\lambda}_{t}$ denoted the number of HFMD cases at month $t$. The regression coefficients were estimated by the 
Figure 1. Map of Viet Nam showing Dak Lak province (in dark green area)

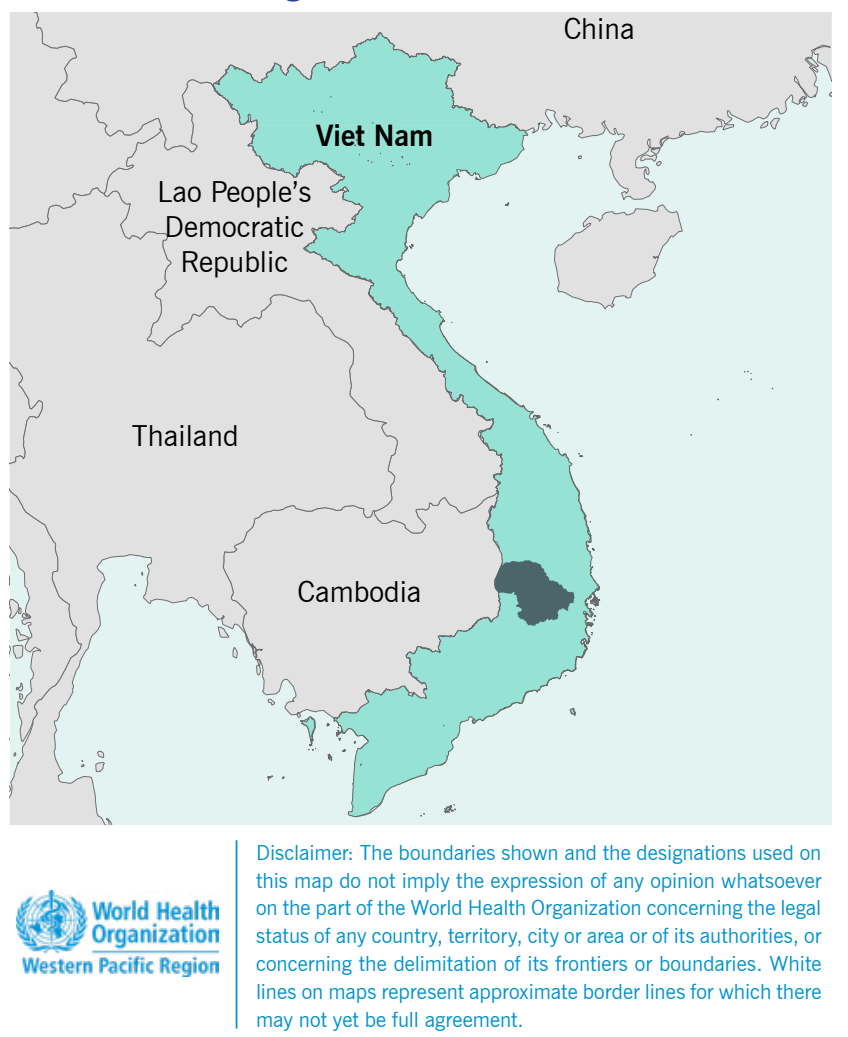

method of maximum likelihood by using the $\mathrm{R}$ program package. ${ }^{17}$

\section{Ethics statement}

The study was approved by the Scientific Committee of the University of Medicine and Pharmacy at Ho Chi Minh City, Viet Nam as Decision No. 66/YTCC-DT dated 25 March 2014.

\section{RESULTS}

In 2012 through 2013, the National Disease Surveillance System reported there were 7128 HFMD patients in Dak Lak: 5191 patients in 2012 (incidence rate: 289 per 100000 population) and 1937 patients in 2013 (186 per 100000 population).

Although HFMD patients were reported throughout the year, the number of HFMD cases increased from April through May and September through October (Fig. 2), accounting for about $50 \%$ of total HFMD cases. The average number of patients per month was 25 in the rainy season (from May through October) and 15 in the dry season (from November through April of the next year). Compared to the dry season, on average, there were 10 more patients per month in the rainy season $(95 \% \mathrm{Cl}: 4-15)$ cases $(P<0.005)$.

Data analysis showed that the number of HFMD cases was associated with climate factors (Tables 2 and 3 ). Due to multicollinearity among average temperature, maximum temperature and minimum temperature of these variables, only average temperature and humidity were included in the final model. The correlation coefficients ( $r$ ) of average temperature with maximum and minimum temperature were 0.77 and 0.82 , respectively; between humidity and evaporation, the correlation coefficient $(r)$ of humidity and evaporation was 0.87 .

Results of univariate analysis showed a significant increase in the risk of HFMD when average temperature, humidity and rainfall were elevated. The study found a

Table 1. Climate change and occurrence of hand, foot and mouth disease cases stratified by month, Dak Lak province, Viet Nam, 2012-2013

\begin{tabular}{|c|c|c|c|c|c|c|c|c|c|}
\hline Month & $\begin{array}{l}\text { No. of } \\
\text { cases } \\
\text { (a) }\end{array}$ & $\begin{array}{c}\text { Average } \\
\text { temperature }\left({ }^{\circ} \mathrm{C}\right) \\
\text { (b) }\end{array}$ & $\begin{array}{l}\text { Maximum } \\
\text { temperature }\left({ }^{\circ} \mathrm{C}\right) \\
\text { (b) }\end{array}$ & $\begin{array}{l}\text { Minimum } \\
\text { temperature }\left({ }^{\circ} \mathrm{C}\right) \\
\text { (b) }\end{array}$ & $\begin{array}{l}\text { Humidity (\%) } \\
\text { (b) }\end{array}$ & $\begin{array}{l}\text { Rainfall } \\
\text { (mm) } \\
\text { (b) }\end{array}$ & $\begin{array}{l}\text { Evaporation } \\
\text { (mm) } \\
\text { (b) }\end{array}$ & $\begin{array}{l}\text { Sunshine } \\
\text { (hours) } \\
\text { (b) }\end{array}$ & $\begin{array}{l}\text { Wind speed } \\
\text { (m/s) } \\
\text { (b) }\end{array}$ \\
\hline January & 261 & 20.8 & 29.9 & 15.2 & 82.0 & 15.4 & 96.1 & 198.1 & 2.9 \\
\hline February & 239 & 22.5 & 33.1 & 16.5 & 79.0 & 9.4 & 105.0 & 224.5 & 2.7 \\
\hline March & 436 & 24.3 & 34.0 & 16.8 & 76.7 & 50.9 & 124.4 & 248.4 & 2.4 \\
\hline April & 604 & 25.5 & 34.6 & 20.0 & 79.1 & 170.5 & 101.1 & 233.4 & 1.7 \\
\hline May & 658 & 25.6 & 33.5 & 20.3 & 81.5 & 193.7 & 89.5 & 252.9 & 1.4 \\
\hline June & 504 & 24.7 & 31.4 & 20.7 & 85.7 & 223.4 & 68.1 & 163.1 & 2.1 \\
\hline July & 427 & 24.2 & 31.5 & 19.7 & 86.8 & 206.2 & 65.5 & 163.8 & 1.8 \\
\hline August & 527 & 24.2 & 31.5 & 20.2 & 85.3 & 184.8 & 73.5 & 166.3 & 2.4 \\
\hline September & 1017 & 23.7 & 31.1 & 20.0 & 88.0 & 525.3 & 52.0 & 131.9 & 1.8 \\
\hline October & 1285 & 23.2 & 30.2 & 18.0 & 84.8 & 163.1 & 69.4 & 182.9 & 1.8 \\
\hline November & 849 & 23.2 & 30.6 & 17.6 & 85.3 & 97.5 & 72.8 & 188.9 & 2.3 \\
\hline December & 321 & 20.9 & 29.2 & 14.9 & 82.7 & 16.6 & 87.0 & 202.1 & 2.5 \\
\hline
\end{tabular}

a Data are total number of cases tallied from 2012 through 2013.

b Data are averages across two years (2012-2013). 
Figure 2. Distribution of hand, foot and mouth disease cases by month, Dak Lak province, Viet Nam, 2012-2013

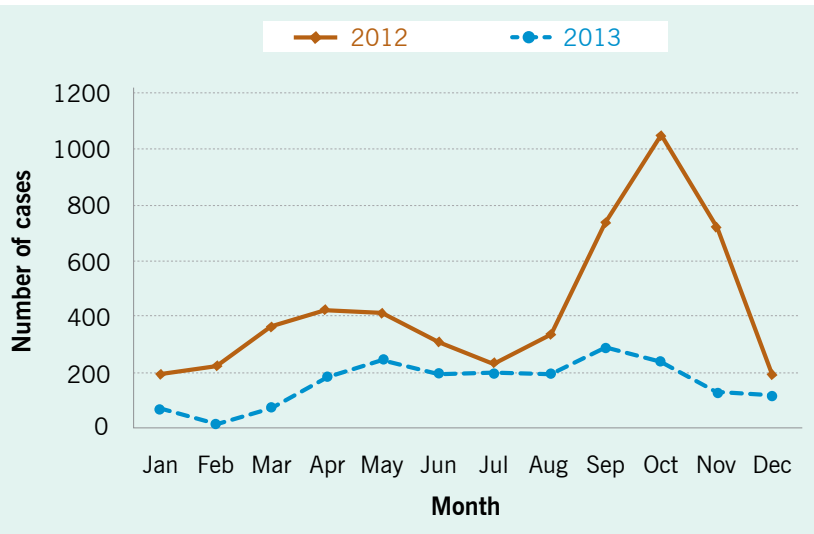

reverse association between HFMD and sunshine duration and wind speed. In the multivariable Poisson regression model, results indicated that average temperature, rainfall and sunshine duration had significantly positive effects on the number of HFMD cases. The risk of HFMD, however, reduced when wind speed increased. Humidity was not significantly associated with HFMD case counts in the multivariable model.

\section{DISCUSSION}

The present study demonstrated a seasonal pattern of HFMD occurrence in a Central Highlands province of with a higher number of cases occurring in the rainy season. This was one of a few studies examining the association between meteorological factors and HFMD occurrence in Viet Nam. Our finding is consistent with what has been reported in a previous study conducted in southern Viet Nam. ${ }^{4}$ However, exact reasons for the relationship between weather and HFMD are limited. Meteorological factors could affect occurrences of infectious disease via survival and transmission of pathogens in the environment as well as population activities and behaviour. ${ }^{18-20}$

Table 2. Risk factors for hand, foot and mouth disease in Dak Lak province: univariate analysis

\begin{tabular}{lccc}
\hline Risk factor & $\begin{array}{c}\text { Unit of } \\
\text { comparison }\end{array}$ & $\begin{array}{c}\text { Risk ratio } \\
(95 \% \mathrm{Cl})\end{array}$ & p-value \\
\hline $\begin{array}{l}\text { Average } \\
\text { temperature }\end{array}$ & Per $1{ }^{\circ} \mathrm{C}$ increase & $1.18(1.16-1.21)$ & $<0.001$ \\
Humidity & Per $5 \%$ increase & $1.14(1.11-1.18)$ & $<0.001$ \\
Rainfall & Per $200 \mathrm{~mm}$ increase & $1.26(1.23-1.29)$ & $<0.001$ \\
Sunshine & Per 60 hours increase & $0.95(0.91-0.98)$ & $<0.001$ \\
Wind speed & Per $1 \mathrm{~m} / \mathrm{s}$ increase & $0.66(0.63-0.69)$ & $<0.001$ \\
\hline
\end{tabular}

Pathophysiology of enteroviruses was found to be affected by temperature, humidity and surface of fomites. ${ }^{19}$ This study found that within the range of average temperatures in the region, a one-degree higher average temperature was associated with an increase of $6 \%$ in the number of HFMD cases. Studies from Hong Kong SAR (China) and Japan revealed similar findings: a positive association between average temperature and number of HFMD cases. ${ }^{7-11,20-22}$ Moreover, a study in Hong Kong SAR (China) showed that warm weather in winter might increase the number of HFMD cases. ${ }^{23}$ High temperatures could increase the growth of enteroviruses and also interfere with inactivation and recovery of enteroviruses. ${ }^{24,25}$

HFMD has seasonality. In temperate regions, the number of patients who are infected with enteroviruses rises in summer. ${ }^{11,25,26}$ In subtropical and tropical regions, enteroviruses circulate throughout the year and elevate during the rainy season. ${ }^{1}$ This study found each $200 \mathrm{~mm}$ increase in rainfall was associated with a $19 \%$ increased risk of HFMD onset. This finding is also consistent with that found in previous studies from other countries. ${ }^{6,28,29}$ A possible explanation is that high rainfall makes soil moist, which may facilitate viral persistence and spreading. ${ }^{25,30}$ In contrast, some studies in China did not support the association between rainfall and HFMD. ${ }^{8,9}$

Although some previous studies suggested that humidity was associated with HFMD, ${ }^{6-8,10,11}$ the current study did not find a statistically significant association between humidity and the number of HFMD cases each month. The difference between the current study and previous studies that showed a positive effect was the use of monthly data. Another study using monthly data also concluded no association with the number of HFMD cases. $^{28}$

Table 3. Risk factors for hand, foot and mouth disease in Dak Lak province: multivariable analysis

\begin{tabular}{lccc}
\hline Risk factor & $\begin{array}{c}\text { Unit of } \\
\text { comparison }\end{array}$ & $\begin{array}{c}\text { Risk ratio } \\
(95 \% \mathrm{Cl})\end{array}$ & p-value \\
\hline $\begin{array}{l}\text { Average } \\
\text { temperature }\end{array}$ & Per $1{ }^{\circ} \mathrm{C}$ increase & $1.06(1.03-1.08)$ & $<0.001$ \\
Humidity & Per $1 \%$ increase & $1.06(0.99-1.12)$ & 0.053 \\
Rainfall & Per $200 \mathrm{~mm}$ increase & $1.19(1.14-1.24)$ & $<0.001$ \\
Sunshine & Per 60 hours increase & $1.14(1.07-1.22)$ & $<0.001$ \\
Wind speed & Per $1 \mathrm{~m} / \mathrm{s}$ increase & $0.77(0.73-0.81)$ & $<0.001$ \\
\hline
\end{tabular}


In agreement with results from other studies that showed the effect of increased sunshine, ${ }^{12,31}$ our findings showed that the risk of HFMD increased by $14 \%$ per 60 hours of increase in sunshine duration. However, another study showed a negative correlation between sunshine duration and HFMD infection; ${ }^{2}$ this disparity needs further researches to provide more evidence. For wind speed, this study denoted a negative association with the number of HFMD cases: $1 \mathrm{~m} / \mathrm{s}$ increase in wind speed leads to a decrease of $23 \%$ in the risk of HFMD. A possible reason is that months with higher wind speed in Dak Lak were often from December through February, which is the dry season with lower temperature. These factors could have an effect on the dispersal and persistence of pathogens in the environment.

The current study had some limitations: HFMD epidemics have been shown to occur in two- to three-year cycles, ${ }^{31}$ and the two-year period in our study might not be adequate to identify the cycle of enteroviruses and the effects of climate change on HFMD in an ecological analysis. It would be useful to conduct a longer study and conduct time series analysis to detect the natural cycle of HFMD outbreaks in this region. Data based on surveillance systems might be underestimated. To our knowledge, there were several HFMD patients treated in private clinics that were not recorded. In addition, HFMD patients with mild self-limiting or unclear symptoms were not diagnosed as HFMD and were not notified to the HFMD surveillance system.

\section{CONCLUSION}

HFMD is a seasonal health-related challenge in Dak Lak province and other geographical areas with the same climatic characteristics. Understanding the association between HFMD and meteorology is important to predict epidemic trends. Future studies should explore the association between other meteorological factors and the incidence of HFMD to provide more evidence for new policies to be developed. Health departments should use more meteorological data to predict the number of HFMD cases, to identify periods of high risk for HFMD outbreaks and increase health communications during outbreaks. The data also suggest that the occurrence of HFMD in this region is likely the result of multiple causes that remain to be delineated; we recommend that research be conducted to describe a more complete picture of risk factors for HFMD development.

\section{Funding}

The authors received no specific funding for this study.

\section{Conflicts of interests}

The authors declare that they have no competing interests. Every author was involved in drafting the article and revising its intellectual content.

\section{References}

1. A guide to clinical management and public health response for hand, foot and mouth disease (HFMD). Geneva: World Health Organization; 2011. Available from: http://www.wpro.who.int/ publications/docs/GuidancefortheclinicalmanagementofHFMD. pdf

2. Gui J, Liu Z, Zhang T, Hua Q, Jiang Z, Chen B, et al. Epidemiological characteristics and spatial temporal clusters of hand, foot, and mouth disease in Zhejiang Province, China, 2008-2012. PLoS One. 2015 Sep 30;10(9):e0139109. doi:10.1371/journal. pone.0139109 pmid:26422015

3. Hand, foot, and mouth disease situation update number 471. Manila: WHO Regional Office for the Western Pacific; 22 September 2015. Available from: http://www.wpro.who.int/emerging_diseases/hfmd_biweekly_20150922.pdf

4. Van Tu P, Thao NTT, Perera D, Truong KH, Tien NTK, Thuong $\mathrm{TC}$, et al. Epidemiologic and virologic investigation of hand, foot, and mouth disease, southern Vietnam, 2005. Emerg Infect Dis. 2007 Nov;13(11):1733-41. doi:10.3201/eid1311.070632 pmid:18217559

5. Viet Nam Ministry of Health. Statistic Yearbook Communicable Diseases 2013. Hanoi: Thoi Dai Publisher; 2014.

6. Chen C, Lin H, Li X, Lang L, Xiao X, Ding P, et al. Short-term effects of meteorological factors on children hand, foot and mouth disease in Guangzhou, China. Int J Biometeorol. 2014 Sep;58(7):160514. doi:10.1007/s00484-013-0764-6 pmid:24258319

7. Hu M, Li Z, Wang J, Jia L, Liao Y, Lai S, et al. Determinants of the incidence of hand, foot and mouth disease in China using geographically weighted regression models. PLoS One. 2012;7(6):e38978. doi:10.1371/journal.pone.0038978 pmid:22723913

8. Huang Y, Deng T, Yu S, Gu J, Huang C, Xiao G, et al. Effect of meteorological variables on the incidence of hand, foot, and mouth disease in children: a time-series analysis in Guangzhou, China. BMC Infect Dis. 2013 Mar 13;13(1):134. doi:10.1186/14712334-13-134 pmid:23497074

9. Li T, Yang Z, Di B, Wang M. Hand-foot-and-mouth disease and weather factors in Guangzhou, southern China. Epidemiol Infect. 2014 Aug;142(8):1741-50. doi:10.1017/S0950268813002938 pmid:24267476

10. Onozuka D, Hashizume M. The influence of temperature and humidity on the incidence of hand, foot, and mouth disease in Japan. Sci Total Environ. 2011 Dec 1;410-411:119-25. doi:10.1016/j. scitotenv.2011.09.055 pmid:22014509

11. Ma E, Lam T, Wong C, Chuang SK. Is hand, foot and mouth disease associated with meteorological parameters? Epidemiol Infect. 2010 Dec;138(12):1779-88. doi:10.1017/S0950268810002256 pmid:20875200 
12. Chang HL, Chio CP, Su HJ, Liao CM, Lin CY, Shau WY, et al. The association between enterovirus 71 infections and meteorological parameters in Taiwan. PLoS One. 2012;7(10):e46845. doi:10.1371/journal.pone.0046845 pmid:23071650

13. Zheng S, Wang M, Wang S, Shang K, Hu L, Dong J. "Effect of meteorological conditions on occurrence of hand, foot and mouth disease in Wuwei City, Northwestern China," 2011 4th International Conference on Biomedical Engineering and Informatics (BMEI), Shanghai, 2011, pp. 1893-1895. Available from: https:// ieeexplore.ieee.org/document/6098727

14. Feng $\mathrm{H}$, Duan $\mathrm{G}$, Zhang $\mathrm{R}$, Zhang W. Time series analysis of hand-foot-mouth disease hospitalization in Zhengzhou: establishment of forecasting models using climate variables as predictors. PLoS One. 2014 Jan 31;9(1):e87916. doi:10.1371/journal. pone.0087916 pmid:24498221

15. Viet Nam Ministry of Health. Circular No. 54/2015/TT-BYT, guidance on notification, reporting and declaration of communicable diseases issued on Dec 28, 2015. In Vietnamese: https://thukyluat.vn/vb/thong-tu-54-2015-tt-byt-che-do-thong-tin-bao-cao-khaibao-benh-dich-benh-truyen-nhiem-49342.html

16. The National Center for Hydro-meteorological Forecasting. Available from: http://www.nchmf.gov.vn/Web/en-US/105/92

17. R Core Team. R: A language and environment for statistical computing. Vienna: R Foundation for Statistical Computing; 2018. Available from: https://www.R-project.org/

18. Kuhn K, Campbell-Lendrum D, Haines A, Cox J. Using climate to predict infectious disease epidemics. Geneva: World Health Organization; 2005. Available from: https://www.who.int/globalchange/ publications/infectdiseases/en/

19. Abad FX, Pintó RM, Bosch A. Survival of enteric viruses on environmental fomites. Appl Environ Microbiol. 1994 Oct;60(10):370410. pmid:7986043

20. Dong W, Li X, Yang $\mathrm{P}$, Liao $\mathrm{H}$, Wang $X$, Wang $\mathrm{Q}$. The effects of weather factors on hand, foot and mouth disease in Beijing. Sci Rep. 2016 Jan 12;6(1):19247. doi:10.1038/srep19247 pmid:26755102

21. Zhang Z, Xie X, Chen X, Li Y, Lu Y, Mei S, et al. Short-term effects of meteorological factors on hand, foot and mouth disease among children in Shenzhen, China: Non-linearity, threshold and interaction. Sci Total Environ. 2016 Jan 1;539:576-82. doi:10.1016/j. scitotenv.2015.09.027 pmid:26386448
22. Wang H, Du Z, Wang X, Liu Y, Yuan Z, Liu Y, et al. Detecting the association between meteorological factors and hand, foot, and mouth disease using spatial panel data models. Int J Infect Dis. 2015 May;34:66-70. doi:10.1016/j.ijid.2015.03.007 pmid:25770912

23. Ma E, Lam T, Chan KC, Wong C, Chuang SK. Changing epidemiology of hand, foot, and mouth disease in Hong Kong, 2001-2009. Jpn J Infect Dis. 2010 Nov;63(6):422-6. pmid:21099093

24. Yeager JG, O'Brien RT. Enterovirus inactivation in soil. Appl Environ Microbiol. 1979 Oct;38(4):694-701. pmid:44178

25. Rajtar B, Majek M, Polański Ł, Polz-Dacewicz M. Enteroviruses in water environment-a potential threat to public health. Ann Agric Environ Med. 2008;15(2):199-203. pmid:19061255

26. van der Sanden S, Koopmans M, Uslu G, van der Avoort $H_{\text {, }}$ Dutch Working Group for Clinical Virology. Epidemiology of enterovirus 71 in the Netherlands, 1963 to 2008. J Clin Microbiol. 2009 Sep;47(9):2826-33. doi:10.1128/JCM.00507-09 pmid:19625480

27. Wang JF, Guo YS, Christakos G, Yang WZ, Liao YL, Li ZJ, et al. Hand, foot and mouth disease: spatiotemporal transmission and climate. Int J Health Geogr. 2011 Apr 5;10(1):25. doi:10.1186/1476-072X-10-25 pmid:21466689

28. Wang $Y$, Feng $Z$, Yang $Y$, Self $S$, Gao $Y$, Longini IM, et al. Hand, foot, and mouth disease in China: patterns of spread and transmissibility. Epidemiology. 2011 Nov;22(6):781-92. doi:10.1097/ EDE.0b013e318231d67a pmid:21968769

29. Lin H, Zou H, Wang Q, Liu C, Lang L, Hou X, et al. Short-term effect of El Niño-Southern Oscillation on pediatric hand, foot and mouth disease in Shenzhen, China. PLoS One. 2013 Jul 23;8(7):e65585. doi:10.1371/journal.pone.0065585 pmid:23935817

30. Wei J, Hansen A, Liu Q, Sun Y, Weinstein P, Bi P. The effect of meteorological variables on the transmission of hand, foot and mouth disease in four major cities of Shanxi province, China: a time series data analysis (2009-2013). PLoS Negl Trop Dis. 2015 Mar 5;9(3):e0003572. doi:10.1371/journal.pntd.0003572 pmid:25742504

31. Huang X, Wei H, Wu S, Du Y, Liu L, Su J, et al. Epidemiological and etiological characteristics of hand, foot, and mouth disease in Henan, China, 2008-2013. Sci Rep. 2015 Mar 10;5(1):8904. doi:10.1038/srep08904 pmid:25754970 